\title{
The timing and strength of regional brain activation associated with word recognition in children with reading difficulties
}

\section{Roozbeh Rezaie ${ }^{1 *}$, Panagiotis G. Simos ${ }^{2}$, Jack M. Fletcher ${ }^{3}$, Jenifer Juranek ${ }^{1}$, PaulT. Cirino ${ }^{3}$, Zhimin Li $^{1}$, Antony D. Passaro ${ }^{1}$ and Andrew C. Papanicolaou ${ }^{1}$}

\author{
Department of Pediatrics, Children's Learning Institute, University of Texas Health Science Center at Houston, Houston, TX, USA \\ 2 Department of Psychology, University of Crete, Rethymno, Crete, Greece \\ ${ }^{3}$ Department of Psychology, University of Houston, Houston, TX, USA
}

Edited by:

Srikantan S. Nagarajan, University of California at San Francisco, USA

Reviewed By:

Hidenao Fukuyama, Kyoto University, Japan

Peter Sörös, University of Western Ontario, Canada

\section{*Correspondence:}

Roozbeh Rezaie, Department of Pediatrics, Children's Learning Institute, University of Texas Health Science

Center at Houston, 1333 Moursund Street, H-114, Houston, TX 77030,

USA.

e-mail: roozbeh.rezaie@uth.tmc.edu
The study investigates the relative degree and timing of cortical activation across parietal, temporal, and frontal regions during performance of a continuous visual-word recognition task in children who experience reading difficulties ( $N=44, \mathrm{RD})$ and typical readers $(N=40, N I)$. Minimum norm estimates of regional neurophysiological activity were obtained from magnetoencephalographic recordings. Children with RD showed bilaterally reduced neurophysiological activity in the superior and middle temporal gyri, and increased activity in rostral middle frontal and ventral occipitotemporal cortices, bilaterally. The temporal profile of activity in the RD group, featured near-simultaneous activity peaks in temporal, inferior parietal, and prefrontal regions, in contrast to a clear temporal progression of activity among these areas in the $\mathrm{NI}$ group. These results replicate and extend previous MEG and fMRI results demonstrating atypical, latency-dependent attributes of the brain circuit involved in word reading in children with reading difficulties.

Keywords: reading, dyslexia, magnetoencephalography, functional brain imaging, middle temporal gyrus

\section{INTRODUCTION}

Among several explanations of developmental reading difficulties $(\mathrm{RD})$, the presence of a core deficit in the ability to mentally represent and manipulate the sounds of the language (phonological awareness) appears to account for a significant amount of variance in word-level reading scores, especially during the earlier stages of reading acquisition. The ultimate goal of reading, however, is automatic recognition of words and comprehension of their meaning (Gough and Tumner, 1986; Share and Stanovich, 1995; Berninger et al., 2006), which involves a variety of other skills such as vocabulary and working memory (Kaplan et al., 1998; O'Shaughnessy and Swanson, 1998; Willcutt et al., 2001; Storch and Whitehurst, 2002; Ouellette and Sénéchal, 2008). Although in each individual with RD several alternative or complementary factors may account for such difficulties, the observation that RD is often found in children with intact or even superior intelligence and oral (non-phonological) language skills indicates that $\mathrm{RD}$ is associated with functional deficits specific to the brain circuitry that supports reading.

With the advent of functional neuroimaging methods, it has become possible to detect differences in the cerebral activation patterns associated with processes such as phonological decoding and word recognition between RD and non-impaired readers (NI). In particular, evidence from positron emission tomography (PET) and functional magnetic resonance imaging (fMRI) studies suggested that performance deficits in children with $\mathrm{RD}$ is paralleled by hypoactivation in several distinct regions critical for reading ability, including the superior (BA 22) and middle (BA 21) temporal gyri, the inferior parietal lobule [supramarginal and angular gyri (BA 40/39)] and the ventral portion of occipitotemporal cortex (mainly in the left hemisphere; BA 37; Temple et al., 2001; Shaywitz et al., 2002; Cao et al., 2006; Hoeft et al., 2007; for a recent review and meta-analysis see Maisog et al., 2008). An associated finding of either increased or decreased activation in prefrontal (mainly left inferior frontal, IFG) regions has also been reported in these studies.

In addition to PET and fMRI, magnetoencephalography, also known as magnetic source imaging (MSI), is an alternative neuroimaging technique that offers information both on spatial localization and on the timing (latency) of neurophysiological processes. The capacity of MSI to generate spatial maps of language-specific cortex has been validated through direct comparisons with invasive cortical mapping procedures in large-scale clinical populations (e.g., Papanicolaou et al., 2004; Kamada et al., 2007).

Over the course of several studies we have used MSI to differentiate between children with RD and NI readers during execution of both explicit phonological decoding (Simos et al., 2000b, 2002a, 2007), and continuous visual-word recognition tasks (silent real word reading; Simos et al., 2000a). In the latter study the magnitude of neurophysiological activity in left hemisphere posterior temporal (superior and middle temporal gyri) and inferior parietal regions (supramarginal gyrus) was significantly reduced among children with severe $\mathrm{RD}$ as compared to children with average to above average reading achievement. Children with RD also showed increased activity in homologous right hemisphere regions. Another reported feature of aberrant profiles in children with $\mathrm{RD}$ on activation tasks involving pseudoword reading involves the relative timing of regional activation, such that the early occipitotemporal (visual association cortex) activity was immediately followed by early engagement of prefrontal activity and only later by, activation of temporoparietal cortex. 
Earlier MEG studies of RD suffered from a number of potential limitations. One potential limitation was that spatiotemporal activation profiles were obtained by iterative application of the single equivalent dipole model (Sarvas, 1987). While this method has been routinely applied to estimate source locations for sensory- and language-related magnetic fields, and has been subjected to external validation against invasive diagnostic techniques (Szymanski et al., 2001; Papanicolaou et al., 2004; Kamada et al., 2007), a single-dipole model may not fully represent the observed field distributions, a particular problem for modeling brain activation in complex cognitive tasks involving multiple brain areas. A means of overcoming this potential problem is the application of distributed source models and, in particular, the technique known as minimum-norm estimate (MNE; Hämäläinen and Ilmoniemi, 1994; Moran and Tepley, 2000) chosen in the present study. Furthermore, previous MEG studies (as well as some PET and fMRI studies) were limited by their reliance on participant samples that lacked adequate diversity in terms of socioeconomic status and IQ. Finally, another potential source of experimental confounds in early MEG studies of word recognition was that brain activation profiles were obtained with tasks that placed heavy demands on both word recognition and memory processes, despite evidence that task difficulty may significantly impact the degree of activation in key cortical areas (Cao et al., 2006; Pugh et al., 2008).

The objectives of the current investigation were to (a) replicate and extend previous MEG results on the key anatomical and temporal features of the brain activation profiles associated with silent word reading; and (b) assess the relative importance of timedependent engagement of posterior temporal, inferior parietal, and frontal regions for word recognition in children who are either typical or struggling readers. In order to address some of the limitations of previous studies outlined above: (i) a larger, more representative sample of the general school population was selected; (ii) brain activation profiles were reconstructed in the context of much easier version of the continuous word recognition task used in our previous study (Simos et al., 2000a); and (iii) task-related neurophysiological activity was estimated by application of the MNE technique, mentioned above.

\section{MATERIALS AND METHODS \\ PARTICIPANTS}

The primary target group consisted of 44 children with reading difficulties (RD group) as indicated by scores at or below the 16th percentile (standard score of 85 ) on the basic reading composite (average of word attack and letter-word identification subtest score of the Woodcock-Johnson III; Woodcock et al., 2001). A second group of 40 children, who had never experienced difficulties in reading (NI group), served as the comparison group, obtaining standard scores $\geq 88$ on the reading composite index. All 84 participants had full scale IQ scores $>80$ on the Wechsler (1999) abbreviated scale of intelligence. None of the participants had a history or current diagnosis of ADHD. In addition, all children were screened for the presence of attention and/or hyperactivity/impulsivity problems using one of two parental-report symptom checklists (child behavior checklist, CBCL; Achenbach, 1991; SNAP-IV, Swanson, 1992). All children had $T$ scores on the attention problems CBCL scale below 55 or a score lower than 1.6 on the inattention and hyperactivity-impulsivity scales of the SNAP-IV indicating low risk for ADHD (Chen et al., 1994). As shown in Table 1, the two reading groups were comparable in age, $\mathrm{PIQ}$, gender, ethnicity, and handedness. The differences in VIQ (and FSIQ) are not surprising and found in most behavioral and imaging studies; nonetheless, the average VIQ (and FSIQ) of the group with RD was clearly in the average range.

The potential mediating effects of age on reading-group differences were assessed by treating age as a dichotomous, betweensubjects variable. To ensure adequate cell size, each reading ability group was broken down to two subgroups: younger participants (21 NI and $24 \mathrm{RD}$ ) aged 84-130 months, and older participants (19 NI and $20 \mathrm{RD}$ ) aged 131-180 months. All participants were recruited through ads placed in area schools and presentations of the study by the researchers in parent-teacher association meetings. Parent who expressed an interest in participating in the study were subsequently contacted to schedule a meeting for administering the screening instruments. Following approval of the study by the university of Texas-Health Science Center IRB, all parents were asked to sign an informed consent form while underage participants signed an assent form.

\section{PROCEDURES \\ Tasks}

Each participant was tested on a printed word recognition task, adapted from Simos et al. (2000a). Changes in the selection of the stimuli and the number of targets were made to reduce overall task difficulty and memory load. There were only five target stimuli which were repeated in a different random order, mixed with a different set of 30 distractors (non-repeating words) in each of four blocks of stimuli (for a total of 140 stimuli). Target

Table 1 | Demographic data, educational history, and performance on standardized tests for students with reading difficulties (RD) and non-reading impaired students ( $\mathrm{Nl}$; range, mean and SD in parentheses).

\begin{tabular}{lll}
\hline & NI & RD \\
\hline Gender (boys/girls) & $25 / 15$ & $27 / 17$ \\
Age (months) & $7.0-15.0(11.0 \pm 2.3)$ & $7.7-14.3(11.4 \pm 1.7)$ \\
Ethnicity (Caucasian, H, A-AM²) & $16 / 13 / 11$ & $18 / 14 / 12$ \\
Handedness (R/L) & $35 / 5$ & $37 / 7$ \\
Number of students & - & 10 \\
retained in school & & \\
Number of students receiving & - & 29 \\
special education services $^{*}$ & $86-147(108 \pm 17)$ & $80-128(97 \pm 12)$ \\
VIQ* & $80-117(100 \pm 10)$ & $80-129(97 \pm 13)$ \\
PIO $^{*}$ & $81-130(104 \pm 12)$ & $83-119(97 \pm 10)$ \\
FSIQ $^{*}$ & $88-126(107 \pm 10)$ & $53-85(78 \pm 8)$ \\
WJ-III Reading Composite $^{\dagger}$ & $87-131(107 \pm 12)$ & $59-91(80 \pm 7)$ \\
WJ-III Word Attack $^{\dagger}$ & $87-126(107 \pm 11)$ & $35-88$ (75 \pm 12$)$ \\
WJ-III Letter-Word Identification $^{\dagger}$ & $83-136(112 \pm 14)$ & $20-91$ (73 \pm 14$)$ \\
WJ-III Spelling $^{\dagger}$ & & \\
\hline
\end{tabular}

Pairwise group differences: ${ }^{*} p<0.001,{ }^{\dagger} p<0.0001 .{ }^{2} \mathrm{H}$, Hispanic, A-AM, AfricanAmerican; WJ-III, Woodcock-Johnson III subtests. 
words (age, enjoy, hope, jar, and road) included four monosyllabic and one disyllabic word, and had a mean frequency in the Zeno et al. (1995) G6-7 corpus of 158 occurrences per million (range: 32-194 occurrences). A slightly higher proportion of distractors were disyllabic (40\%) and the remaining monosyllabic, with a mean frequency of occurrence of 150 words per million in the same corpus (range: 18-820). Stimuli were presented for $1 \mathrm{~s}$, one at a time (with a randomly varied interstimulus interval of 3-4 s), through a Sony LCD projector (Model VPL-PX21) on a back-projection screen located approximately $60 \mathrm{~cm}$ in front of the participant, and subtended $1.0-3.0^{\circ}$ and $0.5^{\circ}$ of horizontal and vertical visual angle, respectively. Participants were presented the target words prior to the scan and instructed to read them aloud (to ensure that they could) and to "try to remember the words." During the scan they were presented with the target stimuli mixed with the distractors and asked to raise their index finger "as soon as they saw one of the words they had read before the scan." Responding hand was counterbalanced across blocks of trials. Responses were manually recorded by the experimenter.

\section{Imaging procedures}

Magnetoencephalography recordings were obtained with a wholehead neuromagnetometer array (4-D Neuroimaging, Magnes WH3600) equipped with 248 first-order axial gradiometer coils and housed in a magnetically shielded chamber. The magnetic flux measurements were digitized at $250 \mathrm{~Hz}$, filtered off-line with a bandpass filter between 0.1 and $20 \mathrm{~Hz}$ and subjected to a noise reduction algorithm that is part of the $4 \mathrm{D}$-Neuroimaging software. The single-trial event-related field segments (ERFs) in response to 85-115 stimulus presentations (out of a total of 140 recorded), were averaged after excluding those containing eye movement or other myogenic or mechanical artifacts. Only correct responses were analyzed for targets and non-targets.

To identify the intracranial origin of ERFs the magnetic flux distribution recorded simultaneously over the entire head surface at successive time points ( $4 \mathrm{~ms}$ apart) was analyzed using a minimum norm model to obtain estimates of the time-varying strength of intracranial currents (MNE Software, v. 2.5, http://www.nmr.mgh. harvard.edu/martinos/userInfo/data/sofMNE.php). This method permits detection of simultaneous magnetic sources distributed along the entire cortical surface. The model assumes a continuous distribution of current along the cortical surface which has some minimum norm (Hämäläinen and Ilmoniemi, 1994). Estimated current sources were anatomically constrained by an MRI-derived surface model of each participant's brain (T1-weighted: TR $13.6 \mathrm{~ms}$; TE $4.8 \mathrm{~ms}$; recording matrix $256 \times 256$ pixels, one excitation, $240 \mathrm{~mm}$ field of view, and 1.4-mm slice thickness). This surface model was generated by a fully automated cortical surface reconstruction procedure using FreeSurfer software (Dale et al., 1999) for producing a detailed geometric description (regular tessellation of the cortical surface consisting of equilateral triangles known as vertices) of the gray-white matter boundary of the neocortical mantle and the mesial temporal lobe. Each hemisphere consisted of approximately 150,000 vertices (depending on each subject's cortical surface area). For estimating current sources, the MNE software requires the Freesurfer-derived cortical surface reconstruction for defining the solution source space. A grid-spacing of
$7 \mathrm{~mm}$ was used to construct icosahedrons to decimate the number of vertices from 150,000 to approximately 3,000 per hemisphere. Additionally, the MNE software was used to construct a single compartment boundary element model using triangular tessellations to compute the forward model for a current dipole located at each vertex perpendicular to the cortical surface. The inverse solution was subsequently reduced to obtaining an estimate of the scalar distribution of dipole strength across current sources within orientation-specific cortical patches of vertices (Dale and Sereno, 1993). Co-registration of each MEG dataset with its corresponding MRI dataset was performed using an automated co-registration routine within MNE which aligns digitization points in the MEG headshape file with the fiducial points demarcated on the outer skin surface reconstruction of the MRI.

Based on previous reports on the cortical areas that constitute major components of the brain mechanism for reading in children, the following ROIs were examined (in both hemispheres): superior (BA22) and middle temporal gyri (BA 21), supramarginal gyrus (BA 40), angular gyrus (BA 39), inferior (BA 44/45), rostral middle frontal cortex (BA 46), fusiform gyrus (BA 37), lateral occipitotemporal cortex (BA 19), and mesial temporal cortex (entorhinal and parahippocampal cortices; MTL). The anatomical extent of ROIs was determined automatically using the cortical map provided by Freesurfer (Dale et al., 1999). The program outputs a current estimate measure for each voxel at each 4 -ms time point. This measure is then used to compute the two dependent measures used in the analyses outlined in the following paragraphs. First, the average current across all voxels defining each of the ROIs listed above and across all of the 4 -ms time points comprising 14 successive 50 -ms time bins (100-150, 150-200, etc up to $800 \mathrm{~ms}$ ). Second, the latency (in ms after stimulus onset) when averaged current reached peak amplitude within the entire recording epoch. This approach aimed at (a) determining if reading-group differences in the degree of regional activity were age-, time- and hemisphere-dependent (i.e., more systematic for particular time windows and restricted to one hemisphere), (b) establishing the temporal progression of regional activity in each group of participants, and (c) identifying ROIs and time bins where activity correlated with reading ability (measured through standardized achievement tests and during performance of the activation task in the MEG scanner).

\section{Analyses}

Preliminary analyses indicated that group differences $(\mathrm{RD}>\mathrm{NI}$ ) were present as early as between 0 and $50 \mathrm{~ms}$ after stimulus onset [as indicated by a reading group by ROI interaction, $F(8,672)=59.35$, $p<0.0001$ ] in three ROIs: BA46, BA44/45, and BA37 (in all cases $p<0.0001$ for the simple main effects of reading group). In order to correct for potential group differences in peristimulus activity, current estimates in all time bins between 100 and $800 \mathrm{~ms}$ were adjusted by subtracting the average current during 0-50 ms (to ensure that no stimulus-evoked activity was included) in the corresponding ROI for each participant. The average, adjusted current for each $50 \mathrm{~ms}$ time bin and each ROI was then submitted to an ANOVA with ROI (9), Hemisphere (2), and Time bin (14) as the within subjects variables. Reading group (2) and age group (2) served as the between subjects variables. Significant interactions involving reading group were further evaluated by examining four-way 
(e.g., time by ROI by hemisphere by reading group) or three way interactions (e.g., Time by ROI by reading group) which, if significant, were explored by testing two-way interactions (time by reading group). Significant hemisphere asymmetries in the degree of adjusted regional activity will be mentioned (in the form of Hemisphere or Time by Hemisphere effects), even in the absence of reading group-specific hemisphere effects, in order to facilitate comparisons between the present and findings from previous studies using similar tasks. All ANOVA results were evaluated using the Huynh-Feldt method as a precaution against inhomogeneity of variance problems.

The second set of analyses established the outline of the spatiotemporal profiles of activity for participants in each reading group - essentially the temporal progression of regional activity for each group. The dependent variable in these analyses was the median time point of the 50-ms time bin when average, adjusted MNE current reached peak value. ROIs from both hemispheres were ranked according to peak latency and a series of dependentsample $t$-tests were computed between ROIs (earliest peaking ROI with each subsequent ROI, second earliest ROI with each subsequent ROI, etc), in order to test the hypothesis that regional onset latency differences were statistically significant. In order to control for Type I error for multiple comparisons, all tests were evaluated at $\alpha=0.001$. This procedure was performed separately for each reading group. Results were used to identify sets of ROIs that peaked at approximately the same latency after stimulus onset. When activity did not peak at exactly the same time, statistical tests indicated that peak latencies were not systematically different across regions that formed each set. Activity in the majority of ROIs belonging to a particular set of ROIs peaked significantly earlier than activity in the majority of ROIs in the set of subsequently active regions. Across reading groups two or three sets of successively active ROIs were identified.

The final set of analyses consisted of partial correlations between reading measures and peak latency or average, adjusted current in ROIs (and time bins) where significant reading group differences were revealed by previous analyses. Age and VIQ were entered in these analyses as covariates. Notably, the metric of the degree of regional activation provided by MNE is void of the deviation-from-normality problems permitting the application of linear regression algorithms. Count data are generally more susceptive to deviations from normality and alternatives to linear models are more appropriate (such as the general estimable function procedure). In the case of ECD count data the range of values in a particular region is often very large (e.g., between 0 and 70) with greatly uneven distributions. This problem is especially apparent for regression models.

\section{RESULTS}

\section{IN-SCANNER TASK PERFORMANCE}

Percent hits (percent correct identification of targets) was slightly higher for the NI $(80.3 \pm 14 \%)$ compared to the RD group $(70.5 \pm 17 \%), F(1,82)=3.10, p<0.06)$. A similar trend was found for false alarms $(14.2 \pm 5 \%$ and $17.4 \pm 4 \%$, respectively, $p<0.08)$. Although, the main effect of Age Group did not reach significance on either measure $(p>0.2)$, there was a reading by age group interaction on the percentage of hits, $F(1,82)=4.30, p<0.03$, suggesting that age-related differences in response accuracy were larger among RD (younger: $60.4 \pm 14 \%$, older: $78.3 \pm 16 \%$ ) than NI students (younger: $77.6 \pm 9 \%$, older: $83.6 \pm 10 \%$ ).

\section{MEG DATA}

\section{Spatiotemporal profiles of activity}

Sample snapshots of the activation profiles of two participants, one from the NI group and a second from the RD group in Figure 1, demonstrate notable group differences in the relative timing of regional activity. Activity in both groups peaked initially in ventral and lateral occipitotemporal (LOC, ROIs bilaterally (NI readers: between $175 \pm 54$ and $188 \pm 46 \mathrm{~ms}$, RD readers: between $168 \pm 64$ and $185 \pm 74 \mathrm{~ms}$ ). For the NI group, activity in the left MTG, STG, and SMG peaked after a significant temporal delay (at $217 \pm 66,223 \pm 70$, and $248 \pm 62 \mathrm{~ms}$, respectively). Activity in left hemisphere inferior and middle frontal ROIs peaked significantly later (at $284 \pm 82$ and $289 \pm 79 \mathrm{~ms}$, respectively) than activity in left temporoparietal ROIs. The temporal progression of activity for the RD group was distinct from that of the NI group in that (a) on average, activity in occipitotemporal ROIs and the left MTG (at $206 \pm 69 \mathrm{~ms}$ ) peaked nearly at the same time and (b) although activity in the left STG and SMG peaked significantly later than activity in occipitotemporal ROIs (at $214 \pm 89$ and $259 \pm 107 \mathrm{~ms}$, respectively, as for the NI group), activity peaks in left inferior and middle frontal cortices occurred near simultaneously with temporoparietal ROIs (at $233 \pm 73$ and $249 \pm 87 \mathrm{~ms}$, respectively).

\section{Reading group differences in degree of activity}

The omnibus ANOVA for the degree of activity data revealed a significant Time by ROI by reading group interaction, $F(104,8320)=2.51, p<0.0001$, which was further explored via two-way ANOVAs (time by reading group) separately for each ROI [evaluated at alpha $=0.05 / 9$ (ROIs) $=0.006$ to correct for family-wise Type I error]. There were no interactions of reading with age group.

Group differences as a function of latency are displayed in Figure 2. Significant time by reading group interactions were found for activity (adjusted for peristimulus estimated current) in MTG, $F(13,1066)=4.32, p<0.0001$, and STG, $F(13,1066)=4.99$, $p<0.0001$. Follow-up one-way ANOVAs performed at each successive time bin across hemispheres [evaluated at alpha $=0.05 / 14$ (time bins) $=0.004]$ revealed greater degree of activity for NI than $\mathrm{RD}$ participants during the late portion of the source density waveform [between 200 and $650 \mathrm{~ms}: F(1,82)=30.42$, $p<0.0001$ and $F(1,82)=18.87, p<0.0001$, respectively]. Group effects in the opposite direction $(\mathrm{RD}>\mathrm{NI}$ ) were found in the fusiform and middle frontal ROIs as indicated by time by reading group interactions, $F(13,1066)=4.32, p<0.0001$ and $F(13,1066)=4.00, p<0.0001$, respectively. Follow-up one-way ANOVAs revealed that group differences were significant in the early portion of the source density waveform (150-450 ms) in the fusiform, $F(1,82)=20.76, p<0.0001$, and middle frontal gyri, $F(1,82)=21.69, p<0.0001$.

Given previous reports of hemisphere-dependent readinggroup effects in these areas, marginally significant time by hemisphere by reading group interactions were explored further. One 


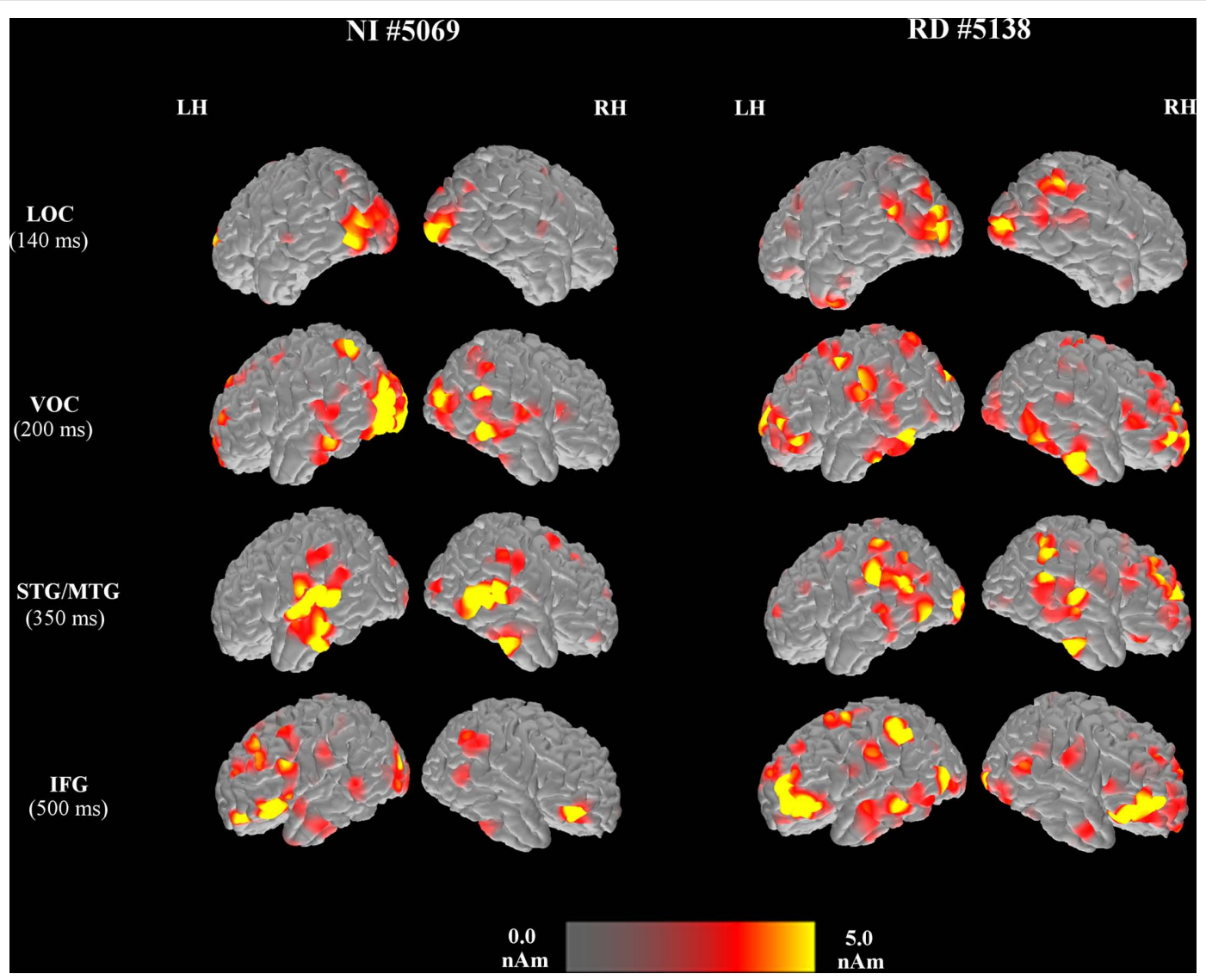

FIGURE 1 | Brain activation map snapshots computed at different time points during the visual-word recognition task from two representative participants [a student from the NI group (left pair of columns) and a student with reading difficulties (right pair of columns)], emphasizing activity in the lateral occipitotemporal (LOC), ventral occipitotemporal
(VOC), superior/middle temporal (STG/MTG), inferior frontal (IFG), and middle frontal regions of the left ( $\mathrm{LH}$ ) and right (RH) hemispheres. The latency, post-stimulus onset that each map was obtained is noted next to the ROI label. Values represent "raw" estimated current (without subtracting the peristimulus current for each ROI). such interaction was found in FUS, $F(13,1066)=2.01, p<0.015$. Inspection of the source current density waveforms in Figure 2 indicates that increased degree of activity for the RD group persisted longer in the $\mathrm{RH}$ as compared to the $\mathrm{LH}$. Indeed the simple main effect of reading group was significant in both hemispheres between 150 and $300 \mathrm{~ms}(p<0.0001)$, but only in the RH between 300 and $450 \mathrm{~ms}[F(1,82)=13.11, p<0.001 ; p>0.05$ in the LH $]$. The waveforms for each reading group were essentially identical between hemispheres in MTG, STG, and middle frontal gyrus (interactions involving hemisphere and reading group were all associated with $p$ values $>0.1$ ) .

Greater degree of left than right hemisphere activity across reading groups was found in the LOC cortex [as indicated by a hemisphere main effect $F(1,82)=7.41, p<0.008]$. Latency-dependent hemispheric asymmetries for both groups, as indicated by significant time by hemisphere effects, were found in MTG [200-300 ms, $F(1,82)=9.01, p<0.003]$, STG $[400-650 \mathrm{~ms}, F(1,82)=10.55$, $p<0.001]$, SMG [300-700 ms, $F(1,82)=12.77, p<0.0001]$, fusiform gyrus [200-350 ms, $F(1,82)=8.32, p<0.004$ ], and middle frontal gyrus [350-550 ms, $F(1,82)=18.54, p<0.0001]$. There were no significant effects involving reading group or hemisphere on peak latency.

\section{Correlations between degree of activity and achievement}

Although the two groups were comparable in age, moderate yet significant negative correlations were found between age and achievement scores (WJ-III word attack, letter-word identification, and spelling), as well as between age and degree of activity in the majority of ROIs (both within and across reading groups). Accordingly, the relation between degree of activity and achievement scores was explored by controlling for the effects of age on both sets of variables. Initially, and in order to preserve the temporal information that is inherent in the MNE time series data, partial correlation coefficients were computed between estimates of neurophysiological activity (adjusted for peristimulus estimated current) for each time bin and ROIs and each of the achievement measures. These analyses were performed separately for NI and $\mathrm{RD}$ children and evaluated at $p<0.005$ in order to control for family-wise Type I error.

For NI readers significant positive correlations were obtained between WJ-III Spelling scores and degree of activity in the following left hemisphere regions: MTG (between 500 and $550 \mathrm{~ms}$; $r=0.47$ ), STG (between 400 and $500 \mathrm{~ms}: r=0.48$ ), and fusiform gyrus (between 200 and $250 \mathrm{~ms}: r=0.49$ ). Significant positive correlations were also noted between two peak latency measures 

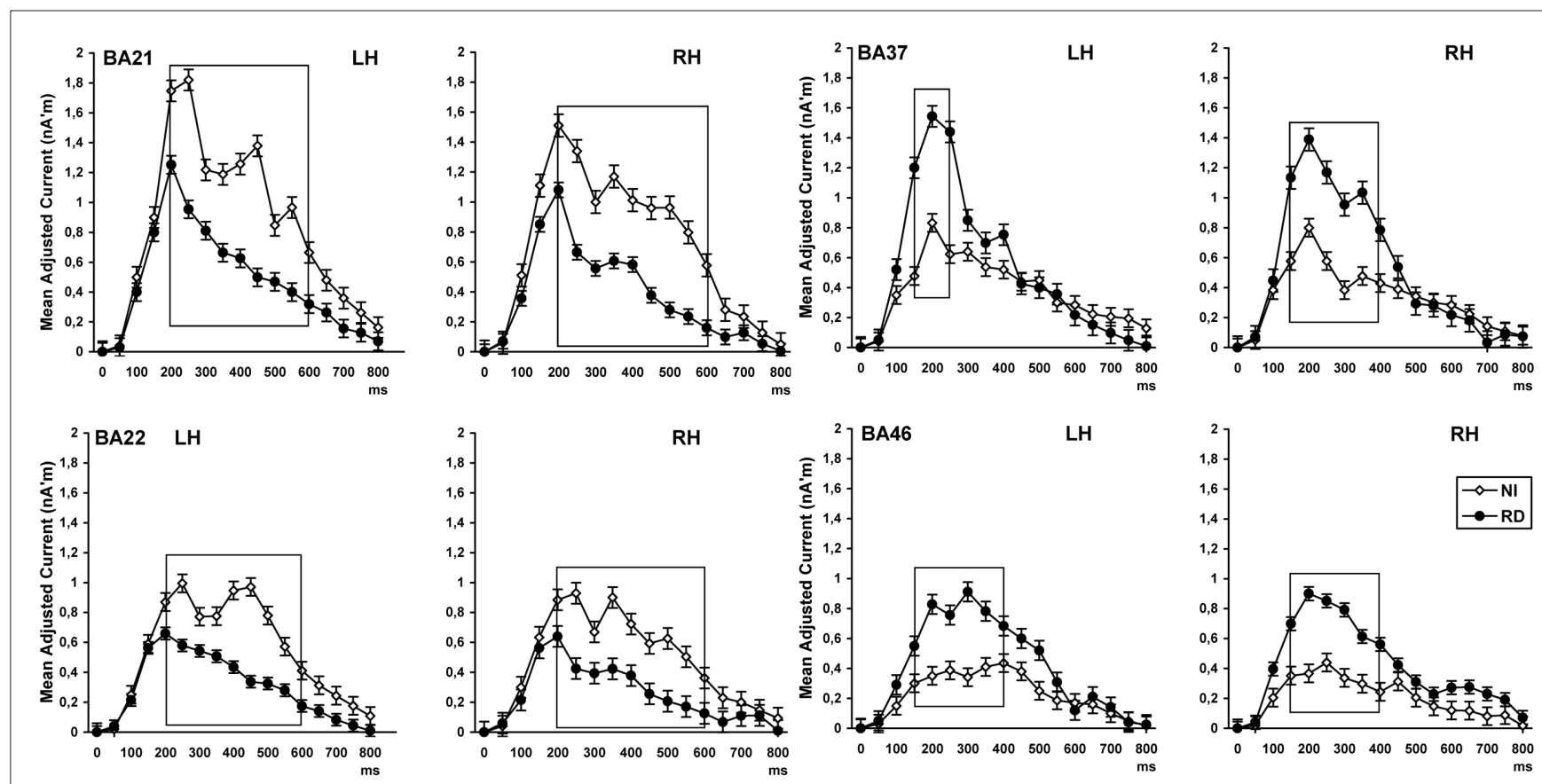

FIGURE 2 |Time course (in $\mathrm{ms}$ after stimulus onset at $\mathbf{0}$ ) of estimated neurophysiological current associated with word reading and recognition in four ROls [in the left (LH) and right hemisphere (RH)]. Values on the vertical axis represent the difference between the peristimulus current in each
$\mathrm{ROI}$ and estimated current in each subsequent time bin. Time windows of significant group differences are marked by boxes. BA22, superior temporal gyrus; BA21, middle temporal gyrus; BA46, rostral middle frontal cortex; BA37, fusiform gyrus. and spelling (left MTL: $r=0.42$ and left fusiform gyrus: $r=0.41$ ). Correlations with letter-word identification scores were generally smaller (ranging between $r=0.18$ and 0.30 ) and failed to reach significance. Correlations with WJ-III word attack scores were negligible $(r<0.13)$. For the RD group, only negative correlations were found between spelling scores and two right hemisphere ROIs, MTL (between 250 and $450 \mathrm{~ms}: r=-0.52$ ) and fusiform gyrus (between 350 and $600 \mathrm{~ms}: r=-0.48)$. There were no significant correlates of achievement measures among peak latency measures in this group.

Each of the MNE estimates of activity listed in the previous paragraph were entered as independent variables in a series of hierarchical multiple regression analyses. The dependent variable in each of these analyses was WJ-III spelling or letter-word identification scores. Age was always entered in the first step of the analysis, degree of activity measures in the second step, and peak latency measures in the third step of each model. For the NI group degree of activity in left posterior temporal cortices (MTG, STG, fusiform gyrus) accounted for $30 \%$ of the variance in spelling scores [Adj $\left.R^{2}=0.30, F(4,36)=4.30, p<0.006\right]$. Adding peak latency measures significantly improved the model [Adj $R^{2}=0.41, F(6,34)=5.30$, $p<0.001]$. A similar pattern emerged for letter-word identification scores with degree of activity measures as predictors [Adj $R^{2}=0.16$, $F(4,36)=2.30, p<0.04]$, and after addition of peak latency measures into the model [Adj $R^{2}=0.39, F(6,34)=4.86, p<0.001$ ]. Figure 3 displays the degree of data fit (concordance between measured spelling performance and standardized predicted spelling scores based on the linear combination of the independent variables in the regression equation). Entering VIQ in the first step along with age did not affect the overall regression results or the individual beta weights of the remaining independent variables. The prediction models for Word Attack scores were not significant. For the $\mathrm{RD}$ group prediction models for each of the three achievement measures did not reach significance ( $p>0.2$ in all cases).

\section{DISCUSSION}

In the present study, distributed source modeling of readingrelated MEG data derived from a large, representative sample of typical and struggling readers partially replicated and extended previous reports (Simos et al., 2000a; Shaywitz et al., 2002; Booth et al., 2007; Pugh et al., 2008) regarding the nature of the functional disruption of the brain mechanism for word reading in RD. Sample selection ensured that the distribution of key demographic variables (age, gender, ethnic background), in addition to handedness and general cognitive ability (measured by PIQ), did not differ significantly between groups. Spatiotemporal brain activation profiles were obtained in the context of a continuous recognition task, the level of difficulty of which was titrated to reduce performance differences between groups compared to previous studies (between 70 and $80 \%$ correct identification of printed words from the training set). This was achieved by using shorter, higher frequency words and a smaller target set compared to our earlier study (Simos et al., 2000a). In this manner demands for both decoding and word recognition as well as memory encoding and retrieval were kept relatively low for both groups. The task was, nevertheless, successful in activating all key reading-related brain areas with clear left hemisphere dominance in their degree of activation as has been our experience with previous language studies (Simos et al., 2001; Papanicolaou et al., 2004). 


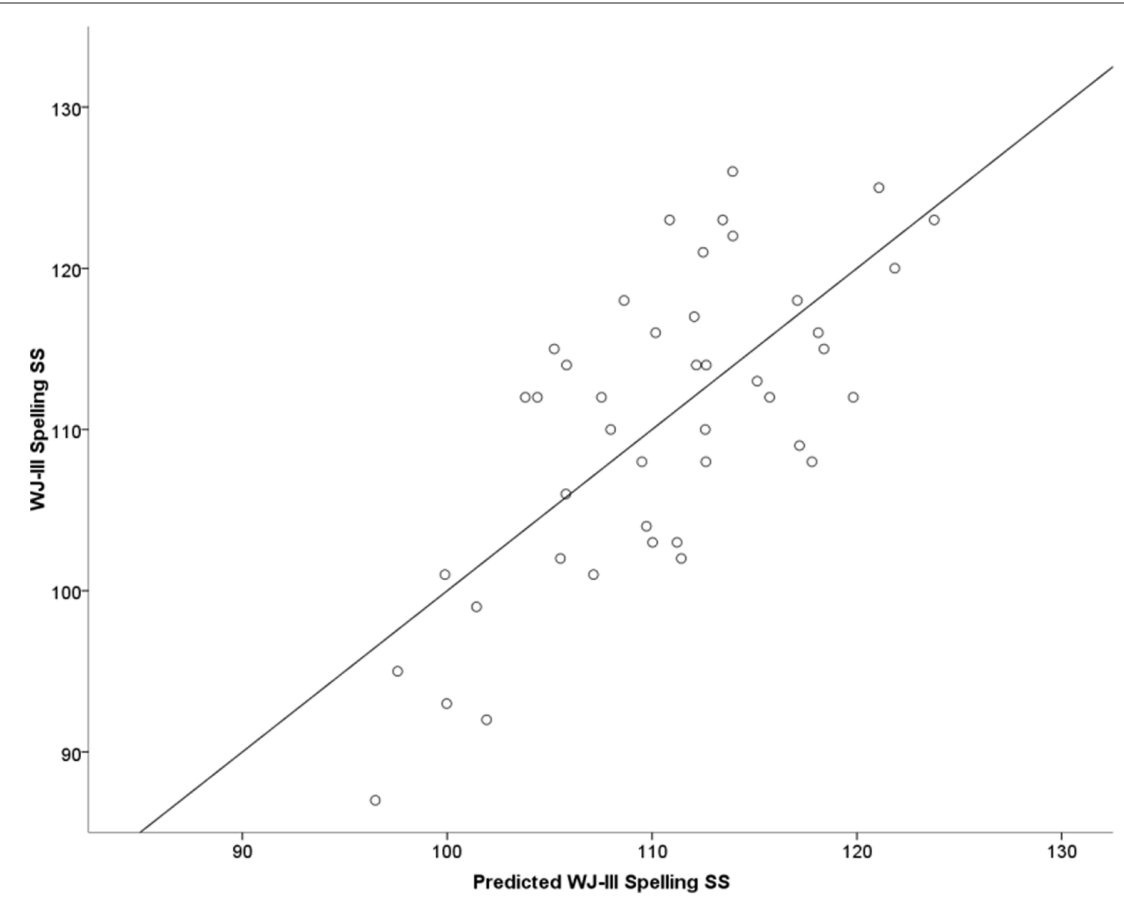

FIGURE 3 | Regression plot of measured Woodcock-Johnson III (WJ-III) standard spelling scores (vertical axis) over predicted standard spelling scores (horizontal axis) based on a linear combination of the following MEG variables: adjusted degree of activity in left posterior ROls (MTG [500-550 ms], STG [400-450 ms], and VOC [fusiform gyrus; 250-300 ms]) and peak latency in the left MTL and VOC among NI students (Adj. $\boldsymbol{R}^{2}=\mathbf{0 . 3 9}$ ). The regression model is described by the following equation: Spelling $=3.065 \times \mathrm{D}_{\mathrm{MTG}}+6.195 \times \mathrm{D}_{\mathrm{STG}}+5.164 \times \mathrm{D}_{\mathrm{VOC}}+0.030 \times \mathrm{L}_{\mathrm{VOC}}+$ $0.040 \times L_{\text {MTL }}+88.436$, where $D$ and $L$ denote degree of activity and peak latency, respectively.
The main findings of the present study can be summarized as follows. Firstly, children with RD showed reduced degree of neurophysiological activity in posterior temporal regions (MTG and STG) in both hemispheres. This activity was associated with relatively late stages of stimulus processing (200-650 ms after stimulus onset). Secondly, children with RD showed significant overactivation of the fusiform gyrus and middle frontal areas (between 150 and $450 \mathrm{~ms}$ ), bilaterally, independent of age. Thirdly, individual differences in the degree and latency of activity in posterior temporal, ventral occipitotemporal (VOC), and mesial temporal regions mapped onto print-related achievement measures.

Although reading group differences in MTG and STG were found in both hemispheres, two additional lines of evidence suggest that disrupted functional brain organization for reading was restricted to the left hemisphere in $\mathrm{RD}$ children. Thus, while the degree of activity in left posterior temporal regions was a significant predictor of reading and spelling skill among NI readers, such an association was not noted among RD children. In the latter group, enhanced activity in right occipitotemporal and mesial temporal regions was associated with lower achievement scores. Importantly, reading-skill related differences in the degree of activity in these regions were evident across the age span covered by the present study (7-15 years). Moreover, for NI children, a clear temporal separation was noted between peaks of neurophysiological activity in left occipitotemporal (lateral and ventral visual association cortices), posterior temporal (middle and superior temporal gyri), and inferior/middle frontal regions. In contrast, the regular temporal progression of activity peaks between left hemisphere occipitotemporal, posterior temporal, and inferior/middle frontal regions was disrupted in the RD group.

\section{TEMPOROPARIETAL CORTEX AND READING ABILITY}

There is ample evidence that neurophysiological processes that take place in the posterior portion of MTG (BA 21) reflect lexi$\mathrm{cal} /$ semantic processing (Damasio and Damasio, 1983; Pugh et al., 1996; Gaillard et al., 2001; Booth et al., 2002; Fiebach et al., 2002; Halgren et al., 2002; Simos et al., 2002b; Turkeltaub et al., 2002; McCandliss et al., 2003; Tyler et al., 2005; Wehner et al., 2007a). These operations may include storage or gaining access to lexical/ semantic information for printed stimuli (Pugh et al., 1996; Fiebach et al., 2002). Damage to this region has been linked to deficits in a variety of tasks tapping into lexical/semantic processing, such as semantic priming (Tyler et al., 2005). Moreover, the onset latency of magnetic activity in this region significantly correlated with pronunciation latency of orthographically exceptional words while this was clearly not the case for regular words and pseudowords (Simos et al., 2002b).

With respect to cortex lying on the lateral and superior aspects of the STG (BA 22), extending posteriorly into the supramarginal gyrus, the bulk of empirical evidence implicates neurophysiological processes taking place in this region in phonological processing of spoken and written language (Beauvois and Derouesne, 1979; Caplan et al., 1995; Papanicolaou et al., 2003; Specht et al., 2003; Majerus et al., 2005). These processes include, but are not limited 
to, storage of sublexical phonological representations, automatic retrieval and short-term maintenance of these representations in consciousness (Hickok and Poeppel, 2000; Wise et al., 2001; Simos et al., 2002b; Mustovic et al., 2003). It should be noted, however, that both imaging and lesion data do not clearly indicate exclusive involvement of the left STG in phonological processing. There is also evidence that this region plays a crucial role for lexical/semantic processing of spoken language. Patients exhibiting the clinical profile of fluent aphasia, which typically results from damage to this region (Benson, 1985; Vignolo, 1988), almost invariably display notable deficits in a variety of experimental tasks tapping into lexical/semantic processing (Hagoort, 1993; Rodd et al., 2005; Janse, 2006). There are also reports that at least in adult experienced readers, the posterior portion of BA 22 is involved in lexical-semantic processing during silent reading tasks (Fiez et al., 1999; Cannestra et al., 2000; Haist et al., 2001; Fiebach et al., 2002; Okada and Hickok, 2006; Simos et al., 2009).

\section{EVIDENCE OF INCREASED ACTIVATION IN RD}

In contrast to the bilateral reduction in MTG and STG activity, a significant increase in the strength of activation in middle frontal regions was noted for the RD group concurring with similar findings from PET and fMRI (Shaywitz et al., 1998; Brunswick et al., 1999; Grunling et al., 2004), as well as our more recent MEG investigations (Simos et al., 2007). It has been suggested that elevated levels of neurophysiological activity in prefrontal regions indicates engagement of cognitive operations supporting alternative strategies employed by individuals with $\mathrm{RD}$ to compensate for a deficiency in mapping the sound structure of printed words through covert articulation (Shaywitz et al., 1998; Shaywitz et al., 2004). However, the putative compensatory increase in prefrontal activity in RD is not a universal finding (e.g., Rumsey et al., 1997; Eden et al., 2004). In a recent meta-analysis of nine fMRI and PET studies Maisog et al. (2008) found no evidence to suggest a universal pattern of bilateral prefrontal hyperactivation in $\mathrm{RD}$, but this meta-analysis involved only adults. In a meta-analysis with no age restrictions, Richlan et al. (2009) reported underactivation of the IFG gyrus and hyperactivity of the primary motor cortex and anterior insula. Several lines of evidence indicate that prefrontal hyperactivation may not reflect a key feature of the brain circuit for reading in $\mathrm{RD}$, but is related to task and age-related processes (Hoeft et al., 2007).

Prefrontal hyperactivation in children with RD in the present study may also reflect additional demands for both encoding and retrieval operations posed by our continuous word recognition task. A comparable finding of increased memory-related prefrontal hemodynamic response among RD children has recently been reported (Vasic et al., 2008). There is ample evidence from lesion and functional imaging studies regarding the critical role played by prefrontal (Knowlton and Squire, 1995; Skinner and Fernandes, 2007; MacPherson et al., 2008) and mesial temporal cortices (Brown and Aggleton, 2001; Turriziani et al., 2004; Wixted and Squire, 2004) for recognition of previously encountered stimuli. The notion that task demands were related to increased prefrontal activity in RD is consistent with our finding that this effect was significantly larger among younger students, given that for this group memory/attention demands are expected to be higher than among older participants, rendering our continuous recognition task even more taxing among young RD students.

Increased strength of activation for children with RD was also found in VOC cortices (anatomically corresponding to the fusiform gyrus). This region is suitable for hosting neurophysiological processes responsible for graphemic processing and also possibly for the integration of orthographic, phonological and morphological information derived from print (McCandliss et al., 2003; Flowers et al., 2004; Pammer et al., 2004; Vigneau et al., 2005). Accumulating evidence suggests that VOC cortices are involved in storing or gaining access to familiar orthographic representations, which may take the shape of "word forms" (Kronbichler et al., 2004; Simos et al., 2009), and play an important role in both word recognition and spelling (Philipose et al., 2007; Mani et al., 2008). In agreement with previous reports, group differences in activity in this region were found during early processing stages at the peaks of the current density waveforms (between approximately 150 and $350 \mathrm{~ms}$; e.g., Tarkiainen et al., 1999; Usui et al., 2009). One possibility is that fusiform activation among struggling readers may reflect increased effort to engage a visual/orthographic strategy for encoding and recognition of the printed word stimuli. This possibility is consistent with behavioral evidence in children and adults with reading disability (Lennox and Siegel, 1996; Milne et al., 2003; McNeil and Johnston, 2004, 2008; Best and Howard, 2005; Zoccolotti et al., 2005; Miller and Kupfermann, 2009). An alternative account of increased VOC activation relies on the putative role of this area in graphemic processing using linguistic constraints (Vigneau et al., 2005; Devlin et al., 2006) and in language functions in general (Schäffler et al., 1994).

\section{TIMING OF REGIONAL ACTIVATION}

Another key finding of the represent study was the lack of temporal differentiation between activity peaks in VOC and the left MTG and also between left temporoparietal and IFG ROIs in the RD group. Similar results have been reported previously in MEG studies with younger struggling readers (Simos et al., 2005, 2007, in press). In contrast, non-impaired readers showed a systematic progression of activity peaks between VOC, middle temporal, temporoparietal, and IFG regions. In the absence of empirical data establishing direct links between the temporal progression of activity between any two cortical regions and anatomical connections between these regions, interpretations of these findings can only be speculative at present. The timing data, however, present an intriguing parallel with findings of reduced white matter integrity in poor readers (Deutsch et al., 2005; Niogi and McCandliss, 2006) and indirect evidence from hemodynamic studies for reduced functional "connectivity" between VOC and temporoparietal regions (Pugh et al., 2000; Cao et al., 2008) and between temporoparietal and frontal regions (Hampson et al., 2006).

\section{COMPARISON WITH PREVIOUS MEG STUDIES OF RD}

A notable difference between the current findings and those of our earlier MEG study (Simos et al., 2000a) concerns the hemispheric profile of reading-group activation differences during the visual-word recognition task. Significant right hemisphere 
predominance of temporoparietal activity had been observed earlier for RD children, whereas in the present study both groups of children demonstrated $\mathrm{L}>\mathrm{R}$ activation of posterior temporal cortices. Moreover, whereas RD children had previously been distinguished by a noticeable reduction in activation of the left temporoparietal cortex and accompanying hyperactivation of the right homotopic region, bilateral group effects were found here, namely reduced activation of the left and right STG and MTG, relative to NI children. Although, bilateral hemodynamic hypoactivation in posterior temporal and inferior parietal areas has sometimes been reported (Rumsey et al., 1997; McCrory et al., 2000; Meyler et al., 2007), these discrepancies merit some consideration.

One possible explanation may concern differences in sample selection: The present investigation employed a more representative sample of children selected from schools as opposed to community recruitment, and a slightly more lenient reading achievement criterion to form the study groups. This account is not supported by additional exploratory analyses comparing two age- and PIQcomparable groups of children derived from the current data set, one with severe $\mathrm{RD}(N=20$, with word attack, letter-word identification, and spelling scores below 75 points) and the second with high-average reading achievement scores (over 95 points on each of the three subtests; $N=22$ ). The results were essentially identical to those from the entire sample without notable increases in the effect size of interactions involving hemisphere.

Another potential explanation may relate to differences in task demands. The task used in the present investigation was significantly easier to perform than the version used in Simos et al. (2000a) as evidenced by comparable performance between reading achievement groups. Evidence from neuroimaging studies in individuals with RD have shown the degree of brain of activity to be affected by reading task difficulty (Cao et al., 2006), including lateralization of STG and MTG activation (Pugh et al., 2008). Word reading tasks, especially if they do not pose specific demands for phonological processing are likely to be more susceptible to the effects of overall task difficulty, and result in reduced hemispheric asymmetries in perisylvian activation (e.g., McCrory et al., 2000). A similar effect appears to hold for auditory processing as well (e.g., Breier et al., 2003; Wehner et al., 2007b).

\section{REFERENCES}

Achenbach, T. M. (1991). Manual for the Child Behavior Checklist/4-18 and 1991 Profile. Burlington, VT: University of Vermont, Department of Psychiatry.

Beauvois, M. F., and Derouesne, J. (1979). Phonological alexia: three dissociations. J. Neurol. Neurosurg. Psychiatr. 42, 1115-1124.

Benson, D. F. (1985). “Aphasia," in Clinical Neuropsychology, eds K. Heilman and E. Valenstein (New York: Oxford University Press), 17-36.

Berninger, V.W.,Abbott, R. D., Vermeulen, K., and Fulton, C. M. (2006). Paths to reading comprehension in at-risk second-grade readers. J. Learn. Disabil. 39, 334-351.
Best, W., and Howard, D. (2005). "The $\mathrm{W}$ and $\mathrm{M}$ are mixing me up": use of a visual code in verbal short-term memory tasks. Brain Cogn. 5, 274-285.

Booth, J. R., Bebko, G., Burman, D. D., and Bitan, T. (2007). Children with reading disorder show modality independent brain abnormalities during semantic tasks. Neuropsychologia 45, 775-783.

Booth, J. R., Burman, D. D., Meyer, J. R., Gitelman, D. R., Parrish, T. B., and Mesulam, M. M. (2002). Modality independence of word comprehension. Hum. Brain Mapp. 16, 251-261.

Breier, J. I., Simos, P. G., Fletcher, J. M., Castillo, E. M., Zhang, W., and Papanicolaou,A.C. (2003). Abnormal

Furthermore, the use of a higher-density gradiometer array in conjunction with distributed source modeling may account for the additional group-related findings in prefrontal and mesial temporal cortices. By affording increased sensitivity to smaller sources (mainly in terms of the spatial extent of their respective magnetic surface maps), the current MEG system was more likely to reveal multiple sources in each hemisphere which were invisible or difficult to model using the single-dipole method. Similarly, the potential for detecting smaller, more extended sources of activation is likely to have been facilitated by the use of distributed source modeling.

\section{CONCLUSION AND FUTURE DIRECTIONS}

Although task demands were intentionally reduced to ensure high levels of performance among students with RD, clear indications of atypical functional organization of the brain mechanism for word recognition were detected. In addition to assessing group differences in average degree of regional neurophysiological activity, our results explored the relation between individual differences in achievement scores and degree of regional activity. Significant positive relations were restricted to the NI group in agreement with recent functional (Hoeft et al. 2007) and anatomical studies (Pernet et al., 2009). These findings further corroborate results from this and previous studies suggesting that atypical functional organization of cortical networks for reading form the core pathophysiology of developmental RD, whereas reliance on operations that take place in prefrontal and right VOC cortices (among other areas) reflects a relatively inefficient mechanism for word recognition. An important caveat of the source mapping approach used in the present study, however, is that ROI selection was restricted by the cortical segmentation procedure available in FreeSurfer, resulting in relatively large ROIs (e.g., the entire extent of MTG). Future studies adopting a voxelbased approach may provide more detailed spatiotemporal data associated with engagement of the brain circuit for reading.

\section{ACKNOWLEDGMENTS}

This research was supported in part by grant P50 HD052117 from the Eunice Kennedy Shriver National Institute of Child Health and Human Development (NICHD). The content is solely the responsibility of the authors and does not necessarily represent the official views of the NICHD or the National Institutes of Health.

activation of temporoparietal language areas during phonetic analysis in children with dyslexia. Neuropsychology 17, 610-621.

Brown, M. W., and Aggleton, J. P. (2001). Recognition memory: what are the roles of the perirhinal cortex and hippocampus? Nat. Rev. Neurosci. 2, 51-61.

Brunswick, N., McCrory, E., Price, C. J., Frith, C. D., and Frith, U. (1999). Explicit and implicit processing of words and pseudowords by adult developmental dyslexics: a search for Wernicke's Wortschatz? Brain 122, 1901-1917.

Cannestra, A. F., Black, K. L., Martin, N. A., Cloughesy, T., Burton, J. S.,
Rubinstein, E., Woods, R. P., and Toga, A. W. (2000). Temporal and topographical characterization of language cortices using intraoperative optical intrinsic signals. Neuroimage 12, 41-54.

Cao, F., Bitan, T., and Booth, J. R. (2008). Effective brain connectivity in children with reading difficulties during phonological processing. Brain Lang. 107, 91-101.

Cao, F., Bitan, T., Chou, T. L., Burman, D. D., and Booth, J. R. (2006). Deficient orthographic and phonological representations in children with dyslexia revealed by brain activation patterns. J. Child Psychol. Psychiatr. 47, 1041-1050. 
Caplan, D., Gow, D., and Makris, N. (1995). Analysis of lesions by MRI in stroke patients with acoustic-phonetic processing deficits. Neurology 45, 293-298.

Chen, W. J., Faraone, S. V., Biederman, J., and Tsuang, M. T. (1994). Diagnostic accuracy of the child behavior checklist scales for attention-deficit hyperactivity disorder: a receiver-operating characteristic analysis. J. Consult. Clin. Psychol. 62, 1017-1025.

Dale, A. M., Fischl, B., and Sereno, M. I. (1999). Cortical surface-based analysis. I. Segmentation and surface reconstruction. Neuroimage 9, 179-194.

Dale, A. M., and Sereno, M. I., (1993). Improved localization of cortical activity by combining EEG and MEG with MRI cortical surface reconstruction: a linear approach. J. Cogn. Neurosci. 5, 162-176.

Damasio, H., and Damasio, A. (1983). The anatomic basis of pure alexia. Neurology 33, 1573-1583.

Deutsch, G. K., Dougherty, R. F., Bammer, R., Siok, W. T., Gabrieli, J. D. E., and Wandell, B. (2005). Children's reading performance is correlated with white matter structure measured by diffusion tensor imaging. Cortex 41, 354-363.

Devlin, J. T., Jamison, H. L., Gonnerman, L. M., and Matthews, P. M. (2006). The role of the posterior fusiform gyrus in reading. J. Cogn. Neurosci. 18, 911-922.

Eden, G. F., Jones, K. M., Cappell, K., Gareau, L., Wood, F. B., Zeffiro, T. A., Dietz, N.A., Agnew, J.A., and Flowers, D. L. (2004). Neural changes following remediation in adult developmental dyslexia. Neuron 44, 411-422.

Fiebach, C. J., Friederici, A. D., Muller, K., and von Cramon, D. Y. (2002). fMRI evidence for dual routes to the mental lexicon in visual word recognition. $J$. Cogn. Neurosci. 14, 11-23.

Fiez, J.A., Balota, D. A., Raichle, M. E., and Petersen, S.E. (1999). Effects of lexicality, frequency, and spelling-to-sound consistency on the functional anatomy of reading. Neuron 24, 205-218.

Flowers, D. L., Jones, K., Noble, K., VanMeter, J., Zeffiro, T. A., Wood, F. B., and Eden, G. F. (2004). Attention to single letters activates left extrastriate cortex. Neuroimage, 21, 829-839.

Gaillard, W. D., Pugliese, M., Grandin, C. B., Braniecki, S. H., Kondapaneni, P., Hunter, K., Xu, B., Petrella, J. R., Balsamo, L., and Basso, G. (2001). Cortical localization of reading in normal children: an fMRI language study. Neurology 57, 47-54.

Gough, P. B., and Tunmer, W. E. (1986). Decoding, reading, and reading disability. Remedial Spec. Educ. 7, 6-10.
Grunling, C., Ligges, M., Huonker, R., Klingert, M., Mentzel, H. J., Rzanny, R., Kaiser, W.A., Witte, H., and Blanz, B. (2004). Dyslexia: the possible benefit of multimodal integration of fMRI and EEG-data. J. Neural Transm. 111, 951-969.

Hagoort, P. (1993). Impairments of lexical-semantic processing in aphasia: evidence from the processing of lexical ambiguities. Brain Lang. 45, 189-232.

Haist, F., Song, A. W., Wild, K., Faber, T. L., Popp, C. A., and Morris, R. D. (2001). Linking sight and sound: fMRI evidence of primary auditory cortex activation during visual word recognition. Brain Lang. 76, 340-350.

Halgren, E., Dhond, R. P., Christensen, N., Van Petten, C., Marinkovic, K., Lewine, J. D., and Dale, A. M. (2002). N400-like magnetoencephalography responses modulated by semantic context, word frequency, and lexical class in sentences. Neuroimage, 17, 1101-1116.

Hämäläinen, M. S., and Ilmoniemi, R. J. (1994). Interpreting magnetic fields of the brain: minimum norm estimates. Med. Biol. Eng. Comput. 32, 35-42.

Hampson, M., Tokoglu, F., Sun, Z, Schafer, R. J., Skudlarski, P., Gore, J. C., and Constable, R. T. (2006). Connectivity-behavior analysis reveals that functional connectivity between left BA39 and Broca's area varies with reading ability. Neuroimage 31, 513-519.

Hickok, G., and Poeppel, D. (2000). Towards a functional neuroanatomy of speech perception. Trends Cogn. Sci. 4, 131-138.

Hoeft, F., Meyler, A., Hernandez, A., Juel, C., Taylor-Hill, H., Martindale, J. L., McMillon, G., Kolchugina, G., Black, J. M., Faizi, A., Deutsch, G. K., Siok, W. T., Reiss, A. L., Whitfield-Gabrieli, S., and Gabrieli, J. D. (2007). Functional and morphometric brain dissociation between dyslexia and reading ability. Proc. Natl. Acad. Sci. U.S.A. 104, 4234-4239.

Janse, E. (2006). Lexical competition effects in aphasia: deactivation of lexical candidates in spoken word processing. Brain Lang. 97, 1-11.

Kamada, K., Sawamura, Y., Takeuchi, F., Kuriki, S., Kawai, K., Morita, A., and Todo, T. (2007). Expressive and receptive language areas determined by a non-invasive reliable method using functional magnetic resonance imaging and magnetoencephalography. Neurosurgery 60, 296-305.

Kaplan, B. J., Dewey, D., Crawford, S. G., and Fisher, G. C. (1998). Deficits in long-term memory are not characteristic of ADHD. J. Clin. Exp. Neuropsychol. 20, 518-528.
Knowlton, B. J., and Squire, L. R. (1995). Remembering and knowing: two different expressions of declarative memory. J. Exp. Psychol. Learn. Mem. Cognit. 21, 699-710.

Kronbichler, M., Hutzler, F., Wimmer, H. Mair, A., Staffen, W., and Ladurner, G. (2004). The visual word form area and the frequency with which words are encountered: evidence from a parametric fMRI study. Neuroimage, 21, 946-953.

Lennox, C., and Siegel, L. S. (1996). The development of phonological rules and visual strategies in average and poor spellers. J. Exp. Child Psychol. $62,60-83$.

MacPherson, S. E., Bozzali, M., Cipolotti, L., Dolan, R. J., Rees, J. H., and Shallice, T. (2008). Effect of frontal lobe lesions on the recollection and familiarity components of recognition memory. Neuropsychologia 46, 3124-3132.

Maisog, J. M., Einbinder, E. R., Flowers, D. L., Turkeltaub, P. E., and Eden, G. F. (2008). A Meta-analysis of functional neuroimaging studies of dyslexia. Ann N. Y. Acad. Sci. 1145, 237-259.

Majerus, S., Linden, M. V., Collette, F., Laureys, S., Poncelet, M., Degueldre, C., Delfiore, G., Luxen, A., and Salmon, E. (2005). Modulation of brain activity during phonological familiarization. Brain Lang. 92, 320-331.

Mani, J., Diehl, B., Piao, Z., Schuele, S. S., Lapresto, E., Liu, P., Nair, D. R. Dinner, D. S., and Lüders, H.O. (2008). Evidence for a basal temporal visual language center: cortical stimulation producing pure alexia. Neurology 71 , 1621-1627.

McCandliss, B. D., Cohen, L., and Dehaene, S. (2003). The visual word form area: expertise for reading in the fusiform gyrus. Trends Cogn. Sci. 7, 293-299.

McCrory, E., Frith, U., Brunswick, N., and Price, C. (2000). Abnormal functional activation during a simple word repetition task: a PET study of adult dyslexics. J. Cogn. Neurosci. 12, 753-762.

McNeil, A. M., and Johnston, R. S. (2004). World length, phonemic, and visual similarity effects in poor and normal readers. Mem. Cognit. 32, 687-695.

McNeil, A. M., and Johnston, R. S. (2008) Poor readers' use of orthographic information in learning to read new words: a visual bias or a phonological deficit? Mem. Cognit. 36, 629-640.

Meyler, A., Keller, T. A., Cherkassky, V. L., Lee, D., Hoeft, F., Whitfield-Gabrieli, S., Gabrieli, J. D., and Just, M. A. (2007). Brain activation during sentence comprehension among good and poor readers. Cerebr. Cortex 17, 2780-2787.
Miller, P., and Kupfermann, A. (2009). The role of visual and phonological representations in the processing of written words by readers with diagnosed dyslexia: evidence from a working memory task. Ann. Dyslexia. 9, 12-33.

Milne, R. D., Nicholson, T., and Corballis, M. C. (2003). Lexical access and phonological decoding in adult dyslexic subtypes. Neuropsychology 17, 362-368.

Moran, J. E., and Tepley, N. (2000). Two dimensional inverse imaging (2DII) of current sources in magnetoencephalography. Brain Topogr. 12, 201-217.

Mustovic, H. K., Scheffler, F., Di Salle, F., Esposito, J. G., Hennig, J., and Seifritz, E. (2003). Temporal integration of sequential auditory events: silent period in sound pattern activates human planum temporale. Neuroimage 20, 429-434.

Niogi, S. N., and McCandliss, B. D. (2006). Left lateralized white matter microstructure accounts for individual differences in reading ability and disability. Neuropsychologia 44, 2178-2188.

Okada, K., and Hickok, G. (2006). Identification of lexical-phonological networks in the superior temporal sulcus using functional magnetic resonance imaging. Neuroreport 17, 1293-1296.

O'Shaughnessy, T. E., and Swanson, H. L. (1998). Do immediate memory deficits in students with learning disabilities in reading reflect a developmental lag or deficit?: a selective meta-analysis of the literature. Learn. Disabil. Q. 21, 123-147.

Ouellette, G., and Sénéchal, M. (2008). A window into early literacy: exploring the cognitive and linguistic underpinnings of invented spelling. Sci. Stud. Read. 12, 195-219.

Pammer, K.,Hansen, P.C., Kringelbach,M. L., Holliday, I., Barnes, G., Hillebrand, A., Singh, K. D., and Cornelissen, P. L. (2004). Visual word recognition: the first half second. Neuroimage 22, 1819-1825.

Papanicolaou, A. C., Simos, P. G., Castillo, E. M., Breier, J. I., Davis, R. N., and Diehl, R. L. (2003). Differential brain activation patterns during perception of voice and tone onset time series: a MEG study. Neuroimage 18, 448-459.

Papanicolaou, A. C., Simos, P. G., Castillo, E. M., Breier, J. I., Sarkari, S., Pataraia, E., Billingsley, R. L., Buchanan, S., Wheless, J., Maggio, V., Maggio, and W. W. (2004). Magnetoencephalography: a non-invasive alternative to the Wada procedure. J. Neurosurg. 100, 867-876.

Pernet, C., Andersson, J., Paulesu, E., and Demonet, J. F. (2009). When all hypotheses are right: a multifocal 
account of dyslexia. Hum. Brain Mapp. 30, 2278-2292.

Philipose, L.E., Gottesman, R. F., Newhart, M., Kleinman, J. T., Herskovits, E. H., Pawlak, M. A., Marsh, E. B., Davis, C., Heidler-Gary, J., and Hillis, A. E. (2007). Neural regions essential for reading and spelling of words and pseudowords. Ann. Neurol. 62, 481-492.

Pugh, K. R., Frost, S. J., Dandak, R., Landi, N., Rueckl, J. G., Constable, R. T., Seidenberg, M. S., Fulbright, R. K., Katz, L., and Mencl, W. E. (2008). Effects of stimulus difficulty and repetition on printed word identification: an fMRI comparison of nonimpaired and reading-disabled adolescent cohorts. J. Cogn. Neurosci. 20, 1146-1160.

Pugh, K. R., Mencl, W. E., Shaywitz, B. A., Shaywitz, S. E., Fulbright, R. K., Constable, R. T., Skudlarski, P., Marchione, K. E., Jenner, A. R., Fletcher, J. M., Liberman, A. M., Shankweiler, D. P., Katz, L., Lacadie, C., and Gore, J. C. (2000). The angular gyrus in developmental dyslexia: task-specific differences in functional connectivity within posterior cortex. Psychol. Sci. 11, 51-56.

Pugh, K. R., Shaywitz, B. A., Shaywitz, S. E., Constable, R. T., Skudlarski, P., Fulbright, R. K., Bronen, R. A., Shankweiler, D. P., Katz, L., Fletcher, J. M., and Gore, J. C. (1996). Cerebral organization of component processes in reading. Brain 119, 1221-1238.

Richlan, F., Kronbichler, M., and Wimmer, H. (2009). Functional abnormalities in the dyslexic brain: a quantitative meta-analysis of neuroimaging studies. Hum. Brain Mapp. 30, 3299-3308.

Rodd, J. M., Davis, M. H., and Johnsrude, I.S. (2005). The neural mechanisms of speech comprehension: fMRI studies of semantic ambiguity. Cerebr. Cortex 15, 1261-1269.

Rumsey, J. M., Nace, K., Donohue, B., Wise, D., Maisog, J. M., and Andreason, P. (1997). A positron emission tomographic study of impaired word recognition and phonological processing in dyslexic men. Arch. Neurol. 54, 562-573.

Sarvas, J. (1987). Basic mathematical and electromagnetic concepts of the biomagnetic problem. Phys. Med. Biol. $32,11-22$.

Schäffler, L., Lüders, H. O., Morris, H. H., and Wyllie, E. (1994). Anatomic distribution of cortical language sites in the basal temporal language area in patients with left temporal lobe epilepsy. Epilepsia 35, 525-528.

Share, D. L., and Stanovich, K. E. (1995). Cognitive processes in early reading development: accommodating individual differences into a model of acquisition. Issues Educ. 1, 1-57.

Shaywitz, B. A., Shaywitz, S. E., Blachman, B. A., Pugh, K. R., Fulbright, R. K., Skudlarski, P., Mencl, W.E., Constable, R. T., Holahan, J. M., Marchione, K. E., Fletcher, J.M., Lyon, G. R., and Gore, J. C. (2004). Development of left occipitotemporal systems for skilled reading in children after a phonologicallybased intervention. Biol. Psychiatry 55, 926-933.

Shaywitz, B. A., Shaywitz, S. E., Pugh, K. R., Mencl, W. E., Fulbright, R. K., Constable, R. T., Marchione, K. E., Fletcher, J. M., Lyon, G. R., and Gore, J.C. (2002). Disruption of posterior brain systems for reading in children with developmental dyslexia. Biol. Psychiatry 52, 101-110.

Shaywitz, S. E., Shaywitz, B. A., Pugh, K. R., Fulbright, R. K., Constable, R. T., Mencl, W. E., Shankweiler, D. P., Liberman, A. M., Skudlarski, P., Fletcher, J. M., Katz, L., Marchione, K. E., Lacadie, C., Gatenby, C., and Gore, J. C. (1998). Functional disruption in the organization of the brain for reading in dyslexia. Proc. Natl. Acad. Sci. U.S.A. 95, 2636-2641.

Simos, P. G., Breier, J. I., Fletcher, J. M., Bergman, E., and Papanicolaou, A. C. (2000a). Cerebral mechanisms involved in word reading in dyslexic children: a magnetic source imaging approach. Cerebr. Cortex 10, 809-816.

Simos, P. G., Papanicolaou, A. C., Breier, J. I., Fletcher, J. M., Foorman, B. R., Bergman, E., Fishbeck, K., and Papanicolaou, A. C. (2000b). Brain activation profiles in dyslexic children during nonword reading: a magnetic source imaging study. Neurosci. Lett. 290, 61-65.

Simos, P. G., Breier, J. I., Fletcher, J. M., Foorman, B. R., Mouzaki, A., and Papanicolaou, A. C. (2001). Agerelated changes in regional brain activation during phonological decoding and printed word recognition. Dev. Neuropsychol. 19, 191-210.

Simos, P. G., Fletcher, J. M., Bergman, E., Breier, J. I., Foorman, B. R., Castillo, E. M., Davis, R. N., Fitzgerald, M., and Papanicolaou, A. C. (2002a). Dyslexiaspecific brain activation profiles become normal following successful remedial training. Neurology 58 , 1203-1213.

Simos, P. G., Breier, J. I., Fletcher, J. M., Foorman, B. R., Castillo, E. M., and Papanicolaou, A. C. (2002b). Brain mechanisms for reading words and pseudowords: an integrated approach. Cerebr. Cortex 12, 297-305.

Simos, P. G., Fletcher, J. M., Sarkari, S., Billingsley, R. L., Denton, C., and
Papanicolaou, A. C. (2007). Altering the brain circuits for reading through intervention: a magnetic source imaging study. Neuropsychology 21, 485-496.

Simos, P. G., Fletcher, J. M., Sarkari, S., Billingsley-Marshall, R. L., Francis, D., Castillo, E. M., Denton, C., and Papanicolaou, A. C. (2005). Early development of neurophysiological processes involved in normal reading and reading disability. Neuropsychology 19, 787-798.

Simos, P. G., Pugh, K., Mencl, E., Frost, S., Fletcher, J. M., Sarkari, S., and Papanicolaou, A. C. (2009). Temporal course of word recognition in skilled readers: a magnetoencephalography study. Behav. Brain Res. 197, 45-54.

Simos, P. G., Rezaie, R., Fletcher, J. M., Juranek, J., Passaro, A. D., Li, Z., Cirino, P. T., and Papanicolaou, A. C. (in press). Functional disruption of the brain mechanism for reading: effects of comorbidity and task difficulty among children with developmental learning problems. Neuropsychology.

Skinner, E. I., and Fernandes, M.A. (2007). Neural correlates of recollection and familiarity: a review of neuroimaging and patient data. Neuropsychologia 45 2163-2179.

Specht, K., Holtel, C., Zahn, R., Herzog, H., Krause, B. J., Motthagy, F. M., Radermacher, I., Schmidt, D., Tellmann, L., Weis, S., Willmes, K., and Huber, W. (2003). Lexical decision of nonwords and pseudowords in humans: a positron emission tomography study. Neurosci. Lett. 345, 177-181.

Storch, S. A., and Whitehurst, G. J. (2002). Oral language and code-related precursors to reading: evidence from a longitudinal structural model. Dev. Psychol. 38, 934-947.

Swanson, J. (1992). School-Based Assessments and Interventions for ADD Students. Irvine, CA: K.C. Publications.

Szymanski, M. D., Perry, D. W., Gage, N. M., Rowley, H. A., Walker, J., Berger, M. S., and Roberts, T. P. (2001) Magnetic source imaging of late evoked field responses to vowels: toward an assessment of hemispheric dominance for language. J. Neurosurg. 94, 445-453.

Tarkiainen, A., Helenius, P., Hansen, P. C., Cornelissen, P. L., and Salmelin, R. (1999). Dynamics of letter string perception in the human occipitotemporal cortex. Brain 122, 2119-2132.

Temple, E., Poldrack, R. A., Salidis, J., Deutsch, G. K., Tallal, P., Merzenich, M. M., and Gabrieli, J. D. (2001). Disrupted neural responses to phonological and orthographic processing in dyslexic children: an fMRI study. Neuroreport 12, 299-307.

Turkeltaub, P. E., Eden, G. F., Jones, K. M., and Zeffiro, T.A. (2002). Meta-analysis of the functional neuroanatomy of single-word reading: method and validation. Neuroimage 16, 765-780.

Turriziani, P., Fadda, L., Caltagirone, C., and Carlesimo, G. A. (2004). Recognition memory for single items and for associations in amnesic patients. Neuropsychologia 42, 426-433.

Tyler, L. K., Marslen-Wilson, W. D., and Stamatakis, E. A. (2005). Differentiating lexical form, meaning, and structure in the neural language system. Proc. Natl. Acad. Sci. U.S.A. 102, 8375-8380

Usui, K., Ikeda, A., Nagamine, T., Matsuhashi, M., Kinoshita, M., Mikuni, N., Miyamoto, S., Hashimoto, N., Fukuyama, H., and Shibasaki, H. (2009). Temporal dynamics of Japanese morphogram and syllabogram processing in the left basal temporal area studied by event-related potentials. J. Clin. Neurophysiol. 26, 160-166.

Vasic, N., Lohr, C., Steinbrink, C., Martin, C., and Wolf, R. C. (2008). Neural correlates of working memory performance in adolescents and young adults with dyslexia. Neuropsychologia 46, 640-648.

Vigneau, M., Jobard, G., Mazoyer, B., and Tzourio-Mazoyer, N. (2005). Word and non-word reading: what role for the visual word form area? Neuroimage 27, 694-705.

Vignolo, L. (1988). "The anatomical and pathological basis of aphasia," in Aphasia, eds F. C. Rose, R. Whurr, and M. A. Wyke (London: Whurr), 227-255.

Wechsler, D. (1999). Wechsler Abbreviated Scale of Intelligence (WASI). San Antonio, TX: The Psychological Corporation.

Wehner, D. T., Ahlfors, S. P., and Mody, M. (2007a). The influence of semantic processing on phonological decisions in children and adults: magnetoencephalography (MEG) study. J. Speech Lang. Hear. Res. 50, 716-731.

Wehner, D. T., Ahlfors, S. P., and Mody, M. (2007b). Effects of phonological contrast on auditory word discrimination in children with and without reading disability: a magnetoencephalography (MEG) study. Neuropsychologia 45, 3251-3262.

Willcutt, E. G., Pennington, B. F., Boada, R., Ogline, J. S., Tunick, R. A., Chhabildas, N. A., and Olson, R. K. (2001). A comparison of the cognitive deficits in reading disability 
and attention-deficit/hyperactivity disorder. J. Abnorm. Psychol. 110, 157-172.

Wise, R. J. S., Scott, S. K., Blank, S. C., Mummery, C. J., Murphy K., and Warburton, E. A. (2001). Separate neural subsystems within 'Wernicke's area'. Brain 124, 83-95.

Wixted, J. T., and Squire, L. R. (2004). Recall and recognition are equally impaired in patients with selective hippocampal damage. Cognit. Affect. Behav. Neurosci. 4, 58-66.
Woodcock, R. W., McGrew, K. S., and Mather, N. (2001). Woodcock-Johnson III Tests of Achievement. Itasca, IL: Riverside.

Zeno, S. M., Ivens, S. H., Millard, R. T., and Duvvuri, R. (1995). Educator's Word Frequency Guide. Brewster, NY: Touchstone Applied Science Associates. Zoccolotti, P., De Luca, M., Di Pace, E., Gasperini, F., Judica, A., and Spinelli, D. (2005). Word length effect in early reading and in developmental dyslexia. Brain Lang. 93, 369-373.
Conflict of Interest Statement: The authors declare that the research was conducted in the absence of any commercial or financial relationships that could be construed as a potential conflict of interest.

Received: 28 January 2011; accepted: 27 April 2011; published online: 16 May 2011. Citation: Rezaie R, Simos PG, Fletcher JM, Juranek J, Cirino PT, Li Z, Passaro $A D$ and Papanicolaou AC (2011) The timing and strength of regional brain activation associated with word recognition in children with reading difficulties. Front. Hum. Neurosci. 5:45. doi: 10.3389/ fnhum.2011.00045

Copyright (ㅇ) 2011 Rezaie, Simos, Fletcher, Juranek, Cirino, Li, Passaro and Papanicolaou. This is an open-access article subject to a non-exclusive license between the authors and Frontiers Media SA, which permits use, distribution and reproduction in other forums, provided the original authors and source are credited and other Frontiers conditions are complied with. 